\title{
Use of Wearable Technology to Measure Influence of Driving Stress on Heart Rate of Professional Drivers

\author{
Sohail Attaur-Rasool', Izaz-ur-Rahman², Wajih-ur-Rehman²,
}

\begin{abstract}
Background: Developments in wearable gadgets provides opportunity to measure human physiological parameters with accuracy and low cost.

Objective: To determine the effect of driving stress on heart rate (HR) among professional drivers with a wrist-worn smart band. Cross-sectiona study conducted in . Department of Medicine B.V. Hospital Bahawalpur from November 2018 to December 2018.

Material and Methods: Thirty professional minivan drivers were recruited, Heart Rate was measured during real-time driving conditions with Xiaomi Mi Band 3; we also recorded HR of passengers during the journey for comparison.

Results: Heart Rate of drivers remained significantly higher as compared to passengers at different times during journey. HR of drivers at 30 min of journeying was $98.8 \pm 19.4,(P=0.0001)$ at 60 min of journeying was $110.8 \pm 16.7,(P=<0.0001)$ at 90 min of journeying was $133.4 \pm 22.5,(P=<0.0001)$ at the end of journeying was $153.9 \pm 19.1$.

Conclusion: Driving is a notable stress factor affecting cardiovascular health.

Keywords : heart rate, driving, smart band, driver.
\end{abstract}

This article may be cited as: Attaur-Rasool S, Izaz-ur-Rahman, Wajih-ur-Rehman. Use of Wearable Technology to Measure Influence of Driving Stress on Heart Rate of Professional Drivers. J Saidu Med Coll Swat 2020;10(1):35-38

\section{INTRODUCTION}

Since the last century, people have been spending large durations of time driving to work and other destinations. Increasingly, researchers have shifted their attention on the impact of driving as a health-related behavior. The process of steering a car and maneuvering it through various traffic situations puts high demands on drivers, both mentally and physically. It has been reported that lengthy traveling in vehicles perpetuates conditions that compromise individuals' health, which includes stress ${ }^{1}$. Stress has psychological origins which leads to changes in several physiological processes in the human body. Chronic stress experienced on daily basis leads to a long-term activation, overload and eventual exhaustion of the counter-balancing hormonal, neural and cardiovascular mechanisms of the body. Physiological measures of mental and physical stress are being successfully used in driving-related human factors research ${ }^{2}$. Heart rate (HR) is a time-tested indicator of cardiovascular function traditionally analyzed by examination of radial pulse. Under normal conditions, HR is entirely regulated by the sinoatrial (SA) node commonly known as the pacemaker of heart. The primary regulators of

1. Nishtar Medical University, Multan.

2. Saidu Medical College, Saidu Sharif, Swat.

3. Bahawal-Victoria Hospital, Bahawalpur.

Correspondence: Dr. Sohail Attaur-Rasool,

BX-87, Street No. 4, New Sadiq Colony, Dubai Palace Road,

Bahawalpur.Email:sohailatta@hotmail.com

Mobile: 03336393910 activity of SA node are the two components of autonomic nervous system namely, the parasympathetic and the sympathetic divisions. The over activity of sympathetic division has been a feature of stress states causing increase in $\mathrm{HR}^{3}$.

Physiological measurements including heart rate $(\mathrm{HR})$, its variability, and blood pressure have been shown to be sensitive to stress. A variety of electronic sensor devices have been developed for HR measurement. However, these systems require pasting of electrodes onto the skin ${ }^{4}$. Wearable HR technology is known as Optical Heart Rate Monitoring (OHRM) which utilizes LED (Light Emitting Diode) lights to measure heart rate. There has been a tremendous influx of fitness bands and smart watches claiming to provide accurate HR during physical activities. These devices are worn on the arm and wrist to detect HR with photoplethysmography (PPG) techniques ${ }^{5}$. When the heart contracts and dilates, the pressure is transmitted as a pulse wave in small blood vessels in the skin. LED lights reflect off the skin to detect that change. Finely tuned software algorithms based on artificial intelligence (AI) are applied to measure heart rate automatically and continuously ${ }^{6}$.

The understanding of health implications of driving and commuting is inadequate despite the fact that driving is ubiquitous worldwide. It is not clear whether the adverse health outcomes of spending time on roads are unique to longdistance commuters in general or to professional drivers specifically. This paper focuses on HR 
monitoring of professional minivan drivers during real-time journey in a vehicle using a wearable device. The analysis of HR could reveal a drivers' occupational stress state so this study was designed to compare the HR of professional drivers and the passengers using a wearable device for measurement of HR.

\section{MATERIALAND METHODS}

This experimental study was conducted at Department of Medicine, Quaid-e-Azam Medical Coll eg e/B. V. Ho sp it al Ba hawalp ur wi th collaboration of Department of Physiology, Nishtar Medical University Multan from November 2018 to December 2018. Approval was obtained from institutional ethical review board. During this period, it was neither too warm nor too cold, thus the influence of temperature on the participants physiological readings was negligible. We conducted a recruitment/survey campaign at APV Minivan Service Bahawalpur in November 2017 in order to recruit study participants. This private minivan service hauls passengers between the cities of Bahawalpur and Multan with a travel distance of $100 \mathrm{~km}$ on 7 -seater Suzuki APV airconditioned vehicles with manual gear shift mechanism. Most of the drivers working in this service have the ownership of vehicles and they usually complete 2-3 roundtrips of $200 \mathrm{~km}$ during a routine day. All participants were required to be active drivers with a minimum of one year of driving experience. A questionnaire designed by the research team included the questions about demographics, health-related behaviors, health conditions, and the use of medication. A purposive, criterion sampling method was used to recruit 30 eligible drivers from 50 participants who volunteered. The criteria of the study was based on selecting apparently healthy male adults who reported no health problem or medical condition. Those currently using any pharmacological agent for any recent $(<4$ weeks) or chronic ailments (diabetes, hypertension, ischemic heart disease etc.) were excluded from the study. Study participants with a BMI in obese category were also excluded. Current and previous smokers were also not included in the study. For comparison we recorded heart rate of one of the passengers of the vehicle being driven by our volunteer driver. Thirty passenger willing to participate in the study was recruited. To avoid any bias, passengers included in the study were having the same inclusion criteria as that of the drivers. All of the drivers and passengers who participated in the study provided written informed consent.

The drivers in our study drove 2 hours on the day of data collection from Bahawalpur to Multan as they would typically do. One researcher rode along in the minivan ensuring proper data collection. The starting time of the drive during all research recordings was early morning hours (8AM to 9AM) when numerous minivans leave the facility. Fares were paid individually by the researcher and the passenger involved in the study. The drivers received their usual salary/commission for the time and effort. The researcher instructed the drivers and passengers to wear and use a wearable HR monitor incorporated in smart band 'Xiaomi Mi Band 3' (Xiaomi Inc., China) an hour before the journey. This band is worn on the wrist with a strap and uses PPG technology to measure HR. The device has a power source of built-in rechargeable Lithium-ion battery and is connected via Bluetooth Version 4.0 to any Android smartphone running Android Version 4.4 and up through the smartphone application 'Mi Fit' (Anhui Huami Information Technology Co. Ltd) available on Google Play platform (Google LLC.). The device was used to record heart rate of subjects at fixed intervals during real-time driving situation. The collected data from wearable activity trackers were transferred to the smartphone and was later analyzed. On each day of data collection, researcher used two different Mi Band 3 one each for the driver and the passenger. After the data collection session was over, each band was connected to a separate smartphone for transfer of data from smart band to the smart phone. We measured BMI \& waist circumference (WC) of our subjects with standardized techniques ${ }^{7}$.

For continuous variables, mean and standard deviation (age, height, weight, BMI) were calculated. Differences in mean values of heart rate were calculated through Student's t-test and its significance was checked through its corresponding P-value. P-value equal to or less than 0.05 had been taken as statistically significant.

\section{RESULTS}

This study recruited 60 male healthy volunteers which comprised of a study-group of 30 professional drivers; our control-group included 30 passengers who were matched to study-group 
for age and anthropometric measurements. We found no statistical difference between the age (35.5 vs. $37.9 \mathrm{yrs}$ ); BMI (28.3 vs. $29.5 \mathrm{~kg} / \mathrm{m}^{2}$ ); and waist circumference of study-group with the control-group respectively, as seen in Table 1.

We compared HR of study-group and controlgroup at six different time points i.e. $\mathrm{t} 1$ (30 min before journey), t2 (at the start of journey), t3 (30 min into journey), t4 (60 min into journey), t5 (90 min into journey) and t6 (end of journey) in Table 2. Our results indicated that before the start of journey, mean HR values of drivers (72.5 bpm) did not significantly differ $(P=0.61)$ from those of passenger $(71.1 \mathrm{bpm})$. At the start of journey, mean HR value of drivers (84.6 bpm) was significantly higher $(P<0.05)$ than those of passengers (72.7 bpm). The trend of higher mean value of $H R$ among drivers as compared to passengers was recorded at the time point of 30 minutes into journey (98.8 bpm vs. $82.3 \mathrm{bpm}, P=$ 0.0001 ). As seen in Table 2, mean HR of drivers continued to be significantly raised 60 minutes into journey (110.8 bpm vs. $87.8 \mathrm{bpm}, P<0.0001)$ as well as 90 minutes into journey (133.4 bpm vs. $92.5 \mathrm{bpm} P<0.0001)$. A similar trend was observed at the end of journey when mean HR of drivers $(153.9 \mathrm{bpm})$ was significantly higher $\quad(P<$ $0.0001)$ than the passengers (105.0 bpm).
Graph 1. Comparison of means of heart rate (bpm) of drivers and passengers

Heart rate (bpm) of drivers and passengers

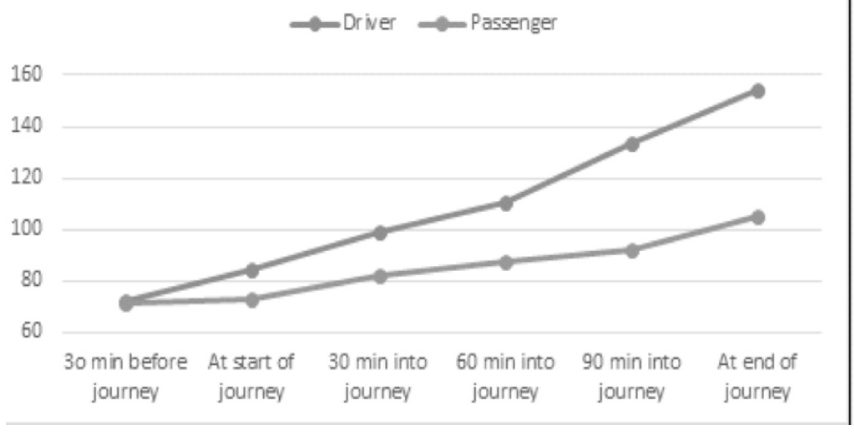

\section{DISCUSSION}

Professional drivers are exposed to several physical hazards (e.g., noise \& air pollution) as well as psychosocial hazards (e.g., conflicts with passengers, waiting for potential passengers, time pressure, long work hours, and traffic jams) while driving on the road $^{8}$. We seized the opportunity to explore and quantify the effects of occupational stressors as a whole on heart rate among a sample of professional minivan drivers in southern Punjab of Pakistan while driving in a realtime scenario. Ambulatory HR during work has been reported in the occupational health literature as a reliable indicator of cardiovascular stress of the workers ${ }^{9}$. A study conducted on ambulatory HR of professional taxi drivers in Los Angeles, USA after eliminating the usual psychosocial strains of driving has reported only minor

\begin{tabular}{|c|c|c|c|}
\hline \multicolumn{3}{|c|}{ Table 1. Comparison of characteristics of study groups } \\
\hline \multirow{2}{*}{ Time } & \multicolumn{2}{|c|}{ Mean \pm SD } & \multirow{2}{*}{$P$-value } \\
\cline { 2 - 3 } & Drivers $(\mathrm{n}=30)$ & Passengers $(\mathrm{n}=30)$ & 0.4012 \\
\hline Age $(\mathrm{yrs})$ & $35.5+9.10$ & $37.9+12.6$ & 0.6466 \\
\hline BMI $\left(\mathrm{kg} / \mathrm{m}^{2}\right)$ & $28.3+8.7$ & $29.5+11.3$ & 0.4087 \\
\hline Waist Circumference $(\mathrm{cm})$ & $99.8+13.5$ & $102.9+15.3$ & \\
\hline \multicolumn{2}{|c|}{ *Significant at <0.05 } \\
\hline
\end{tabular}

\begin{tabular}{|c|c|c|c|}
\hline \multicolumn{2}{|c|}{ Table 2. Comparison of meart SD heart rate (HR) of study groups } \\
\cline { 2 - 3 } Time & \multicolumn{2}{|c|}{ Mean \pm SD $(\mathrm{bpm})$} & \multirow{2}{*}{$P$-value } \\
\cline { 2 - 3 } & Drivers $(\mathrm{n}=30)$ & Passengers $(\mathrm{n}=30)$ & 0.6111 \\
\hline t1 (30 min before journey) & $72.5+10.9$ & $71.1+10.3$ & $0.0004^{*}$ \\
\hline t2 (start of journey) & $84.6+13.4$ & $72.7+10.8$ & $0.0001^{*}$ \\
\hline t3 (30 min into journey) & $98.8+19.4$ & $82.3+9.9$ & $<0.0001^{*}$ \\
\hline t4 (60 min into journey) & $110.8+16.7$ & $87.8+12.7$ & $<0.0001^{*}$ \\
\hline t5 (90 min into journey) & $133.4+22.5$ & $92.5+11.7$ & $<0.0001^{*}$ \\
\hline t6 (end of journey) & $153.9+19.1$ & $105.0+30.6$ & \\
\hline & ${ }^{*} P$-value significant at $<0.05$ & \\
\hline
\end{tabular}


fluctuations in $H R^{10}$. It highlights the fact that the physiological state of drivers driving in a real-life scenario is under a considerable psychic stress which appears to derange cardiovascular autonomic regulatory mechanisms to a higher degree than physical stressors. Many current studies on a driver's mental workload and body response are based on results from driving simulator technology ${ }^{11}$. However, the difference in a driver's physiological response and mental workload between a simulated environment and a real traffic situation should not be overlooked. In modern vehicles with auto-gear shift, power steering and intelligent braking system; the workload associated with modern driving has shifted significantly from the physical to the mental domain. The strength of our study rests on the fact that rather than carrying out tests in a simulated environment, we carried out research on roads in in real driving situations.

A research carried out in China with chest mounted KF2 multi-parameter physiological detector (BodyMon Ltd., China) involving nonprofessional drivers with significant driving experience reported significant increase in heart rate during real driving conditions ${ }^{12}$. We measured HR during real driving using a wrist-worn fitness band incorporating PPG technology. Recent research has shown that $P P G$ yielded very similar heart rates in a trial simultaneously recording HR using electrocardiographic (ECG) technology ${ }^{13,14}$. Based on these findings, PPG technology seems to be accurate and reliable when compared to ECG technology. Furthermore, wearable activity trackers utilizing built-in PPG HR sensors have the advantage to overcome the limitations of the traditional chest strap ${ }^{15}$. PPG technology offers a suitable and cost-effective method to measure HR which is very attractive to research groups who may not be able to afford high-tech gadgets.

The limitations of our study includes nonrandomized sampling method, and the participants in this study were selected from a small geographical area. This study investigated only HR of the subjects which may not be representative of the physiological response of the human body as a whole.

\section{CONCLUSIONS}

Professional drivers have significant higher HR rate during real-time driving situation as compared to fellow non-driving commuters. This study highlights the health implications for professional drivers stressing the importance of routine medical checkups for early detection of cardiovascular abnormalities. A larger study measuring HR for longer durations is warranted to build our understanding of this phenomenon.

\section{REFERENCES}

1. Ding D, Gebel K, Phongsavan P, Bauman AE, Merom D. Driving: a road to unhealthy lifestyles and poor health outcomes. PLoS One. 2014;9(6):9460-2.

2. Fallahi $M$, Motamedzade $M$, Heidarimoghadam $R$, Soltanian AR, Miyake S. Effects of mental workload on physiological and subjective responses during traffic density monitoring: A field study. Applied Ergonomics. 2016;52:95-103.

3. Draghici AE, Taylor JA. The physiological basis and measurement of heart rate variability in humans. J Physiol Anthropol. 2016;35(1):22. doi:10.1186/s40101016-0113-7

4. Wu M, Cao H, Nguyen HL, Surmacz K, Hargrove C. Modeling perceived stress via HRV and accelerometer sensor streams. Conf Proc IEEE Eng Med Biol Soc. 2015;2015:1625-28.

5. Jo E, Lewis K, Directo D, Kim MJ, Dolezal BA. Validation of biofeedback wearables for photoplethysmographic heart rate tracking. J Sports Sci Med. 2016;15(3):540-47.

6. Cadmus-Bertram L, Gangnon R, Wirkus EJ, ThraenBorowski KM, Gorzelitz-Liebhauser J. The Accuracy of Heart Rate Monitoring by Some Wrist-Worn Activity Trackers.Ann Intern Med. 2017;166(8):610-12.

7. Grundy SM, Cleeman JI, Daniels SR, Donato KA, Eckel $\mathrm{RH}$, Franklin BA, et al. American Heart Association. National Heart, Lung, and Blood Institute Diagnosis and management of the metabolic syndrome: an American Heart Association/National Heart, Lung, and Blood Institute Scientific Statement. Circulation. 2005;112:2735-52.

8. Wang PC, Delp L. Health status, job stress and workrelated injury among Los Angeles taxi drivers. Work. 2014;49(4):705-12.

9. Vrijkotte TG, van Doornen LJ, de Geus EJ. Effect of work stress on ambulatory blood pressure, heart rate and heart rate variability. Hypertension. 2000;35(4):880-6.

10. Choi B, Choi S, Jeong J, Lee J, Shu S, Yu N, et al. Ambulatory heart rate of professional taxi drivers while driving without their typical psychosocial work stressors: a pilot study.Ann Occup Environ Med. 2016;28:54.

11. Brookhuis KA, de Waard D. Monitoring drivers' mental workload in driving simulators using physiological measures. Accident Anal Prev. 2010;42(3):898-903.

12. Fu R, Guo Y, Chen Y, Yuan W, Ma Y, Peng J, et al. Research on heart rate and eye movement as indicators of drivers' mental workload. 3rd International Conference on Road Safety and Simulation. 2011;1-20.

13. Weiler DT, Villajuan SO, Edkins L, Cleary S, Saleem JJ. Wearable heart rate monitor technology accuracy in research: a comparative study between PPG and ECG technology. Proc Hum Factors Ergonom Soc. 2017;61(1):1292-96.

14. Evenson KR, Goto MM, Furberg RD. Systematic review of the validity and reliability of consumer wearable activity trackers. Int J Behav Nutr Phys Act. 2015;12(1):159.

15. Shcherbina A, Mattsson CM, Waggott D, Salisbury $H$, Christle JW, Hastie T, et al. Accuracy in wrist-worn, sensor-based measurements of heart rate and energy expenditure in a diverse cohort. J Pers Med. 2017;7(2):. 